\title{
MORFOLOGIA E ANATOMIA DA SEMENTE DE Dictyoloma vandellianum Adr. Juss.(RUTACEAE) ${ }^{1}$
}

\author{
LINDALACERDADASILVA ${ }^{2}$, ADELITAAPARECIDASARTORI PAOL ${ }^{3}$
}

\begin{abstract}
RESUMO - Foram descritos e ilustrados aspectos morfo-anatômicos das sementes de Dictyoloma vandellianum Adr. Juss., visando o conhecimento dos tegumentos, endosperma e embrião. As sementes são reniformes, aladas, acobreadas, mesotestais, exariladas e albuminosas (reserva protéica). O embrião é axial, curvo, dominante, com cotilédones carnosos de reserva protéica, eixo hipocótilo-radícula longo e plúmula reduzida.
\end{abstract}

Termos para indexação: espécie florestal, caracterização morfo-anatômica.

MORPHOLOGY AND ANATOMY OF SEEDS OF Dictyoloma vandellianum Adr. Juss. (RUTACEAE)

\begin{abstract}
The morphology and anatomy of the seeds of Dictyoloma vandellianum Adr. Juss.were described and illustrated, emphasizing the seed coat and development. The seeds are kidney-shaped, copper-colored, winged, mesotestal, exarillate and albuminous (protein storage). The embryo is dominant, axial, curved, white with fleshy cotyledons containing protein grain storage and has long hipocotyl-radicule axis and small plumule.
\end{abstract}

Index terms: forestry specie, morphological and anatomical studies.

\section{INTRODUÇÃO}

Incluída na ordem Rutales, Rutaceae (Engler, 1931) possui aproximadamente 150 gêneros e 1500 espécies distribuídas pelas regiões tropicais e temperadas do mundo todo, sendo mais abundante na América tropical, Sul da África e Austrália (Pirani, 1982). No Brasil existem cerca de 190 espécies (Albuquerque, 1976).

A taxonomia de Rutaceae encontra-se ainda desorganizada e o trabalho de Engler (1931) foi o último sobre tal assunto (Pirani, 1982). No que diz respeito à estrutura da semente, poucos gêneros foram estudados, assim o conhecimento da estrutura das sementes ainda é escasso, principalmente para os gêneros neotropicais, havendo necessidade de mais estudos (Corner, 1976; Boesewinkel, 1977; Beltrati, 1991).

A subfamília Dictyolomatoideae possui apenas um gênero, Dictyoloma. Este gênero possui duas espécies da América do Sul, dentre elas destaca-se Dictyoloma vandellianum de ocorrência no Brasil. Trata-se de uma espécie arbórea com altura variando de 4,0 a 7,0m, com tronco de 20

\footnotetext{
${ }^{1}$ Submetido em 01/04/2005. Aceito para publicação em 18/11/2005;

${ }^{2}$ Bióloga, Dra., Divisão Técnica de Medicina Veterinária e Manejo da Fauna Silvestre, Prefeitura do Município de São Paulo; Rua Santo Amaro, 341/ 1311, CEP: 01315-001, São Paulo-SP, lindlacerda@yahoo.com.br;
}

a 30cm de diâmetro; folhas compostas bipenadas e folíolos verdes com a face inferior mais clara. A madeira é indicada para o fabrico de forros, brinquedos e caixotaria, mas com muita freqüência as árvores são abatidas com a finalidade de uso como lenha ou carvão. Por ser uma árvore de pequeno porte e ornamental, pode ser empregada com sucesso no paisagismo, na arborização de ruas estreitas sob rede elétrica. Além disso, é considerada planta pioneira de rápido crescimento podendo ser indicada para plantios mistos destinados à recomposição de áreas degradadas e de preservação permanente (Pirani, 1982; Lorenzi, 1992).

As informações morfo-anatômicas sobre a semente de Dictyoloma vandellianum são inexistentes sendo apenas encontrados alguns estudos anatômicos para sementes de outras espécies de Rutaceae em Corner (1976), Boesewinkel (1977), Beltrati (1991), Zavaleta-Mancera e Engleman (1991) e Silva e Paoli (2000).

Tendo em vista a importância econômica, paisagística e ecológica desta espécie foi efetuado um estudo morfoanatômico da semente, visando fornecer subsídios para

\footnotetext{
${ }^{3}$ Professora Adjunta, Departamento de Botânica/Instituto de Biociências / UNESP, Caixa Postal 199, CEP: 13506-900, Rio Claro-SP, aapaoli@rc.unesp.br.
} 
observações posteriores de germinação das sementes e morfologia de plântulas que contribuirão para estudos taxonômicos, ecológicos e de análise de sementes.

\section{MATERIAL E MÉTODOS}

O material de Dictyoloma vandellianum Adr. Juss. consistiu de flores e frutos em diferentes estádios de desenvolvimento, coletados de árvores existentes na Reserva Biológica e Estação Experimental de Mogi-Guaçu, no Arboreto da Divisão de Florestas Experimentais do Instituto Florestal de São Paulo, situados no município de Mogi-Guaçu a uma altitude média de $591,277 \mathrm{~m}$, sob as coordenadas geográficas de $22^{\circ} 22^{\prime} 20^{\prime \prime} \mathrm{S}$ e $46^{\circ} 56^{\prime} 32^{\prime \prime W}$ e na Usina Central Energética Moreno, próxima a CELPAV-Celulose e Papel Ltda, no município de Luis Antonio São Paulo, situada a uma altitude média de $675 \mathrm{~m}$, sob as coordenadas geográficas de $21^{\circ} 33^{\prime} 18^{\prime \prime} \mathrm{S}$ e 47²' $16^{\prime \prime} \mathrm{W}$. Após a coleta, o material foi acondicionado em sacos plásticos e transportado para o laboratório. Parte do material coletado foi herborizado, sendo identificado pelo Prof. Dr. José Rubens Pirani (Departamento de Botânica da Universidade de São Paulo-USP) e depositado no Herbarium Rioclarense (HRCB) sob o número 21.049.

Os parâmetros quantitativos foram obtidos em amostras de 100 frutos e 100 sementes, utilizando-se um paquímetro para as medições.

As observações e ilustrações foram feitas utilizando-se estereomicroscópio e microscópio óptico (Zeiss), ambos providos de câmara clara. $\mathrm{O}$ estudo anatômico foi realizado em secções feitas à mão livre, montadas em glicerina $50 \% \mathrm{e}$ material incluído em historresina conforme metodologia descrita por Carmello-Guerreiro (1995), empregando-se como corante o azul de toluidina, em pH 4,0 a 0,05\%, em tampão acetato (Carmello Guerreiro, 1996) montadas em resina sintética entelan e em lâminas semipermanentes, com secções, coradas com fucsina básica e azul de Astra (Roeser, 1972), montadas em glicerina $50 \%$.

Os testes microhistoquímicos foram feitos em material seccionado à mão livre, utilizando-se corantes e/ou reagentes como solução aquosa de cloreto férrico a $10 \%$ adicionada de pequena porção de carbonato de cálcio, para a localização de compostos fenólicos; floroglucina ácida para evidenciar paredes lignificadas (Sass, 1951); Sudam IV para paredes suberificadas, cutinizadas e outros materiais lipídicos; ácido clorídrico e sulfúrico para a identificação de cristais de oxalato de cálcio; reagente de Lugol para amido; vermelho de rutênio para substâncias pécticas e eosina diluída para identificação de proteínas (Johansen, 1940). Para a descrição das sementes foi utilizada a terminologia de Corner (1976) e na descrição do embrião a terminologia de Martin (1946).

\section{RESULTADOS E DISCUSSÃO}

Morfologia da semente - a semente é alada, reniforme, medindo $5,0 \mathrm{~mm}$ de comprimento por $7,5 \mathrm{~mm}$ de largura, acobreada, albuminosa e exarilada. Apresenta duas regiões distintas: núcleo seminífero e ala. O núcleo seminífero é marrom escuro, de superfície rugosa, composta por linhas que se sucedem umas às outras. No núcleo seminífero visualizam-se duas regiões: a região onde se encontra o embrião, sendo este envolvido por uma camada fina de endosperma e outra chamada de corpo basal, separada morfologicamente da região do embrião pelos tegumentos, onde estão situados o hilo e a micrópila, não visíveis. A ala é formada por filamentos estreitos, longos e acobreados. Embrião dominante, axial, curvo, aclorofilado, branco, composto por dois cotilédones longos, carnosos, eixo hipocótilo-radícula longo e plúmula pouco desenvolvida (Figuras 1, 2, 3).

Anatomia e desenvolvimento da semente - a semente provém de óvulo campilótropo, bitegumentado e crassinucelado. O óvulo, em secção longitudinal, constitui-se de dois tegumentos e nucelo. $\mathrm{O}$ tegumento externo possui três camadas distintas: a mais externa formada por uma fileira de células retangulares mais altas que largas; a segunda formada

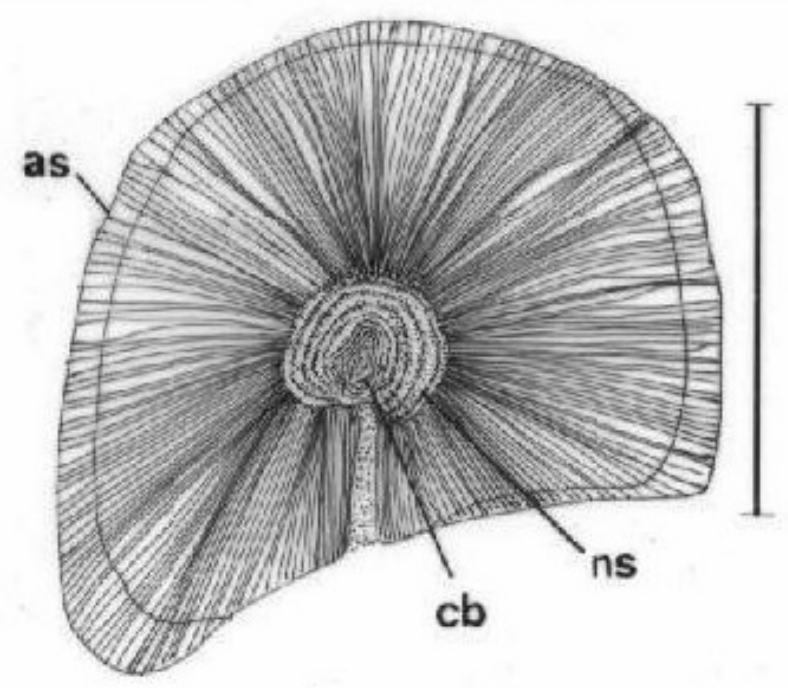

FIGURA 1. Semente madura. Legenda: as - ala; cb-corpo basal; ns - núcleo seminífero. Escala $=5 \mathrm{~mm}$ 


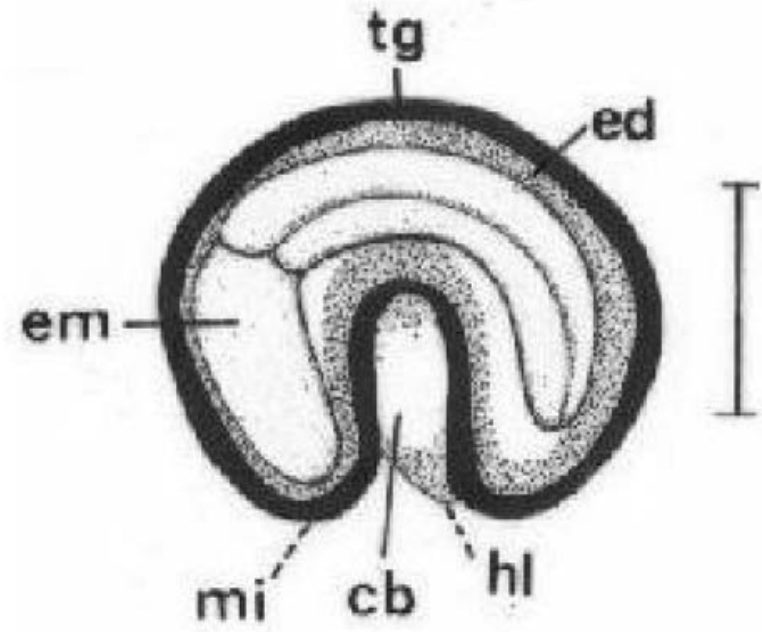

FIGURA 2. Seção longitudinal da semente madura. Legenda: cb - corpo basal; ed - endosperma; em - embrião; hl hilo; mi - micrópila; tg - tegumento. Escala $=5 \mathrm{~mm}$.

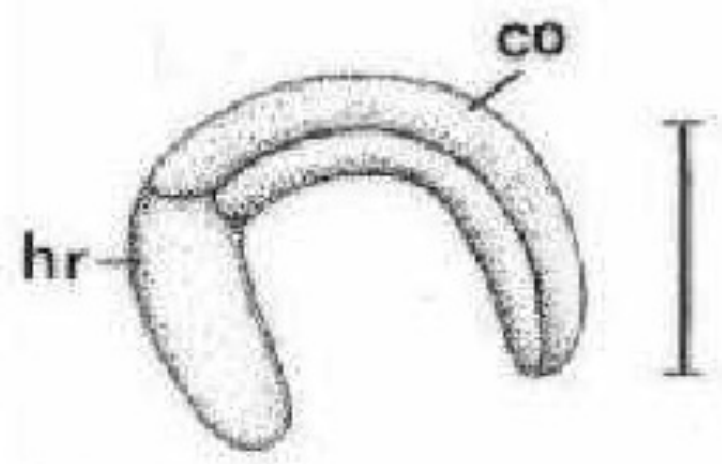

FIGURA 3. Embrião. Legenda: co - cotilédone; hr - eixo hipocótilo-radícula. Escala $=5 \mathrm{~mm}$

por duas fileiras de células retangulares mais largas que altas e paredes mais finas que as da camada mais externa e a terceira, formada por células retangulares, maiores que as da segunda camada e paredes finas. Tegumento interno formado por fileira única de células menores que as do tegumento externo, de formato retangular, são mais largas que altas, possuindo conteúdo de natureza fenólica. $\mathrm{O}$ nucelo possui células poliédricas de paredes finas (Figuras 4, 5).

A semente imatura de frutos com $10,0 \times 7,0 \mathrm{~mm}$, em secção longitudinal, apresenta-se bitegumentada e com nucelo. A testa possui três camadas distintas: a mais externa (exotesta) originada da camada mais externa do óvulo cujas células retangulares diferenciam-se em células alongadas, contendo

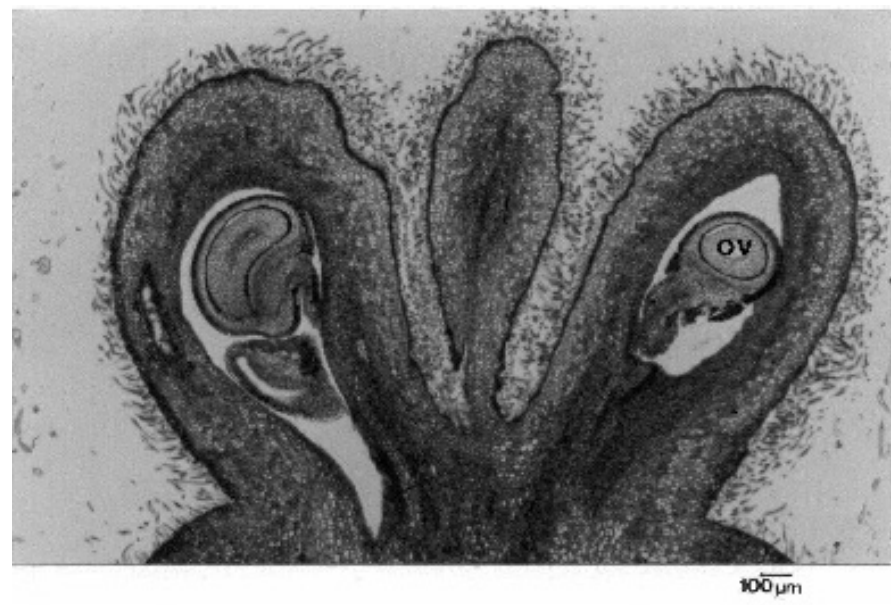

FIGURA 4. Óvulo em secção longitudinal. Legenda: ov - óvulo

conteúdo conspícuo, de natureza fenólica e coloração dourada, constituem a ala da semente. A segunda camada (mesotesta) é formada por quatro a cinco fileiras de células retangulares, mais largas que altas, de paredes finas, núcleos conspícuos e a terceira (endotesta) composta por células de forma poliédrica, de paredes finas e maiores que as da camada anterior. O tégmem, originado do tegumento interno do óvulo, possui uma única fileira de células retangulares e de conteúdo fenólico conspícuo. O nucelo ainda está presente com células poliédricas de paredes finas (Figura 6).

A semente madura possui testa, tégmem, endosperma e embrião. Testa, em secção longitudinal, composta por exo, meso e endotesta. A exotesta possui uma fileira de células compridas, de paredes finas, de conteúdo fenólico conspícuo e de coloração dourada; a meso e endotesta são formadas por quatro a cinco fileiras de células de forma retangular, de paredes espessas, impregnadas por compostos fenólicos que fornecem coloração marrom escura. $\mathrm{O}$ tégmem apresenta-se como no estágio anterior. $\mathrm{O}$ endosperma possui células poliédricas, de paredes finas e com reserva protéica na forma de grânulos. Os cotilédones possuem protoderme, de células com formato retangular e tecido fundamental com reserva protéica, em forma de grânulos e feixes procambiais (Figuras 7,8).

Segundo Corner (1976), os óvulos de Rutaceae são anátropos. Boesewinkel (1977) os descreve como anátropos, hemianátropos ou campilótropos. Outros pesquisadores como, Zavaleta-Mancera e Engleman (1991), verificaram que o óvulo de Casimiroa edulis Llave et Lexarza (subfamília Toddalioideae) é hemianátropo; Beltrati (1991) verificou que o óvulo de Esenbeckia febrifuga (St Hill) A. Juss. ex Mart também é hemianátropo; enquanto que Silva e Paoli (2000) verificaram, em Zanthoxylum rhoifolium, que o óvulo é 


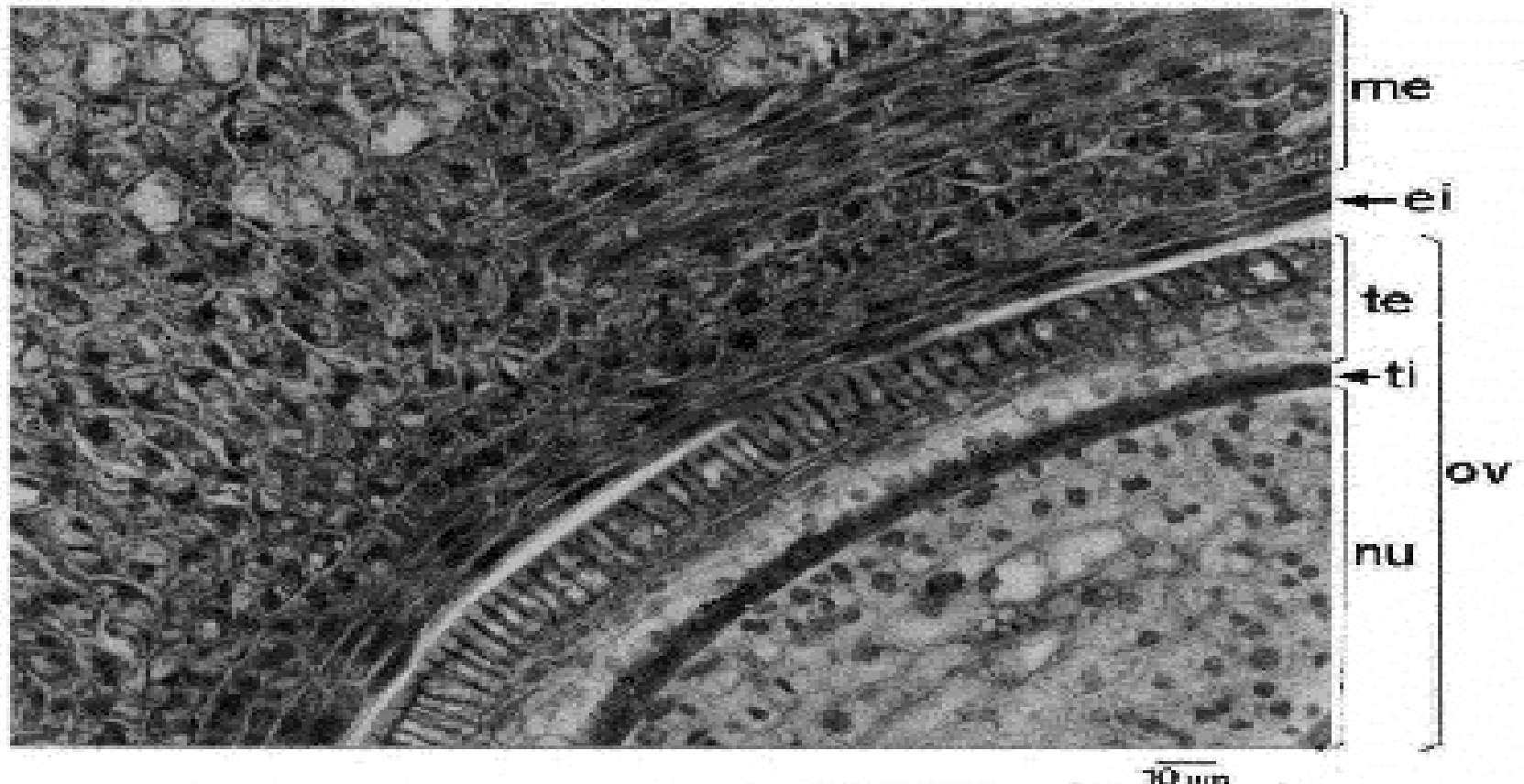

FIGURA 5. Detalhe dos tegumentos do óvulo em secção longitudinal. Legenda: ei - epiderme interna do ovário; me - mesofilo do ovário; nu - nucelo; ov - óvulo; te - tegumento externo; ti - tegumento interno.

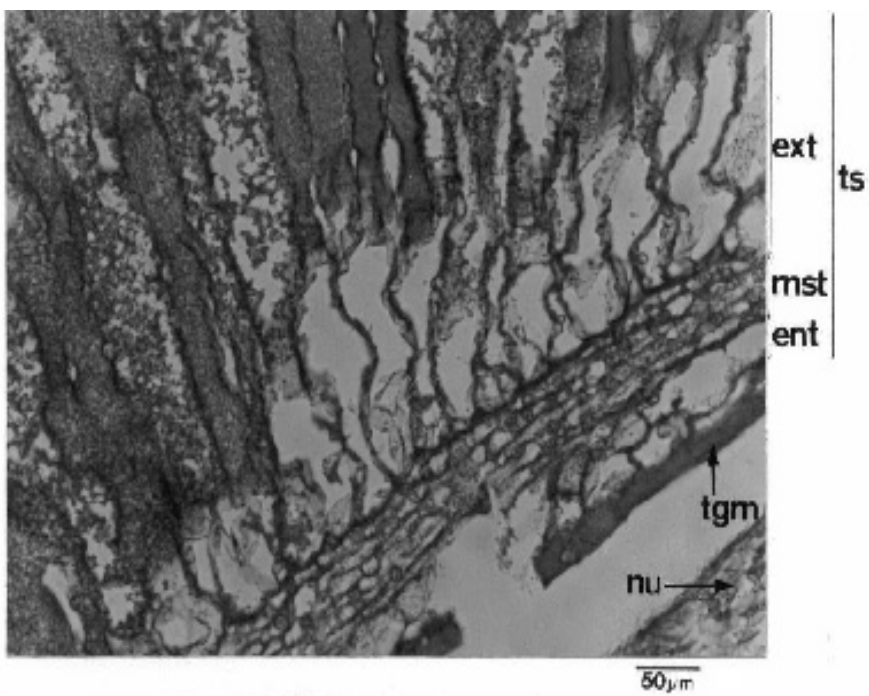

FIGURA 6. Semente imatura. Legenda: ent - endotesta; extexotesta; mst - mesotesta; nu - nucelo; ts - testa; tgm-tégmem.

anátropo. Na espécie em questão, Dictyoloma vandellianum o óvulo é campilótropo, bitegumentado, crassinucelado.

Quanto à estrutura da semente, Corner (1976) elaborou um amplo estudo sobre a estrutura dos tegumentos das sementes de dicotiledôneas e estabeleceu que o caráter distintivo básico do envoltório da semente está na posição e na estrutura da principal camada mecânica presente, composta

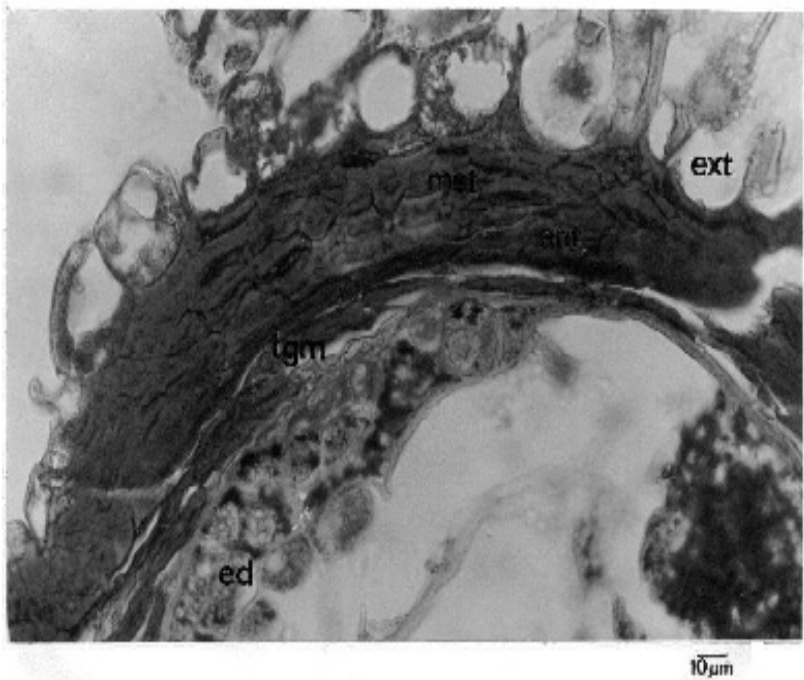

FIGURA 7. Tegumentos e endosperma da semente madura. Legenda: ed - endosperma; ext - exotesta; tgm tégmem.

de células de paredes grossas, mas não necessariamente lignificadas, podendo ter um ou mais estratos de espessura. Em Rutaceae, assim como em outras famílias, o conhecimento sobre a organização da estrutura dos tegumentos das sementes ainda não está completo. Desse modo, classificou as sementes desta família como exo e mesotestais. Beltrati (1991), ao estudar a estrutura dos tegumentos da semente de Esenbeckia 


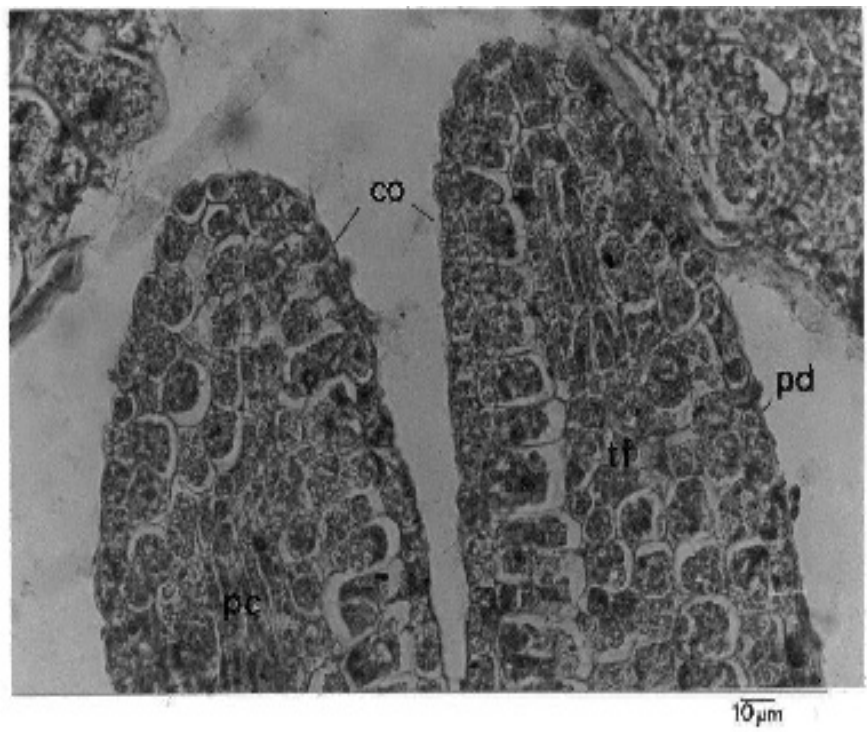

FIGURA 8. Detalhe do cotilédone. Legenda: co-cotilédone; pcprocâmbio; pd-protoderme.

febrifuga, classificou-a como endotestal, devido à presença de uma camada de células em paliçada de paredes grossas nesta região. Neste estudo foi observado que a semente de Dictyoloma vandellianum possui mesotesta composta por células de paredes espessas, sendo, portanto, considerada mesotestal.

As sementes de Rutaceae podem ou não apresentar endosperma quando maduras. Em casos afirmativos, este é do tipo nuclear e contendo reserva lipídica. Os embriões podem apresentar várias formas, sendo retos ou curvos e os cotilédones podem ser finos ou crassos, dobrados ou não (Corner, 1976). Dictyoloma vandellianum possui endosperma e cotilédones com reserva protéica em forma de grânulos, da mesma forma que a semente de Zanthoxylum rhoifolium (Silva e Paoli, 2000). Quanto ao tipo de embrião este é axial, porém arqueado.

$\mathrm{O}$ estudo morfo-anatômico sobre a semente de Dictyoloma vandellianum contribuirá com novas informações sobre as sementes de Rutaceae.

\section{CONCLUSÕES}

Dictyoloma vandellianum apresenta óvulo campilótropo e semente com reserva protéica no endosperma. Embrião axial, arqueado e presença de camada mecânica na mesotesta, caracterizando a semente como mesotestal.

\section{REFERÊNCIAS}

ALBUQUERQUE, B.W.P. Revisão taxonômica das Rutaceae do Estado do Amazonas. Acta Amazônica, Manaus, v. 6, n.3, p.1-67, 1976. Suplemento.

BELTRATI, C.M. Estudo morfoanatômico de sementes e plântulas de Esenbeckia febrifuga (St. Hill.) A. Juss. ex. Mart. (Rutaceae). Naturalia, São Paulo, v.16, [s.n.], p.61-69, 1991.

BOESEWINKEL, F. D. Development of ovule and testa in Rutaceae I: Ruta, Zanthoxylum and Skimmia. Acta Botanica Neerlandica, Amsterdam, v. 26, n. 3, p.193-221, 1977.

CARMELLO-GUERREIRO, S. M. Técnica de inclusão de material vegetal em historresina. Botucatu: Departamento de Botânica da UNESP, 1995. 8p.

CARMELLO-GUERREIRO, S.M. Morfologia, anatomia e desenvolvimento dos frutos, sementes e plântulas de Schinus terebinthifolius Raddi, Lithraea molleoides (Vell) Engl., Myracrodruon urundeuva Fr. Allem. e Astronium graveolens Jacq. (Anacardiaceae). 1996. 90f. Tese (Doutorado em Ciências Biológicas) - Universidade Estadual Paulista, Rio Claro, 1996.

CORNER, E. J. H. The seeds of dicotyledons.v.1.Cambridge: Cambridge University Press, 1976. p.232-237.

ENGLER, A. Rutaceae. In: ENGLER, A.; PRANTL, K. Die Natürlichen Pflanzenfamilien. 2 ed. Leipizig, 1931. tomo 19a, p.187-359.

JOHANSEN, D. A. Plant microtechnique. New York: McGrawHill Book, 1940. 523p.

LORENZI, H. Árvores brasileiras: manual de identificação e cultivo de plantas arbóreas nativas do Brasil. Nova Odessa: Ed. Plantarum, 1992.351p.

MARTIN, A.C. The comparative internal morphology of seeds. American Midland Naturalist, Notre Dame, v.36, n.3, p.513-660, 1946.

PIRANI, J.R. A ordem Rutales na Serra do Cipó, Minas Gerais, Brasil. 1982. 244f. Dissertação (Mestrado em Botânica)Departamento de Botânica, Universidade de São Paulo, São Paulo, São Paulo, 1982.

ROESER, K.R. Die Nadel der Schwarzkiefer-massenprodukt und Kunstwerk der Natur. Mikrokosmos, Frankfurt, v. 61, n. 2, p. 33 36, 1972.

SASS, J.E. Botanical microtechnique. 3.ed. Iowa: State Press, 1951. $228 \mathrm{p}$.

SILVA, L.L ; PAOLI, A.A.S. Caracterização morfo-anatômica da semente de Zanthoxylum rhoifolium Lam.- RUTACEAE. Revista Brasileira de Sementes, Campinas, v. 22, n.2, p.250-256, 2000.

ZAVALETA-MANCERA, H.A. ; ENGLEMAN, E.M. Anatomía de la semilla de Casimiroa edulis (Rutaceae), "zapote blanco", durante su desarrollo. Boletin Sociedad Botanica México, México, v.51, [s.n.], p. 67-81, 1991. 